\title{
Morphometric study of the root anatomy in furcation area of mandibular first molars
}

\author{
Andréa Marcia MARCACCINI' ${ }^{1}$ Ângela PAVANELO ${ }^{2}$, Andressa Vilas Boas NOGUEIRA ${ }^{3}$, João Antonio Chaves de \\ SOUZA $^{3}$, Hélio Ferraz PORCIÚNCULA ${ }^{4}$, Joni Augusto CIRELLI ${ }^{5}$
}

\begin{abstract}
1- DDS, MSc, PhD, Department of Diagnosis and Surgery, Araraquara Dental School, UNESP - Univ. Estadual Paulista, Araraquara, SP, Brazil.
2- DDS, Private Practice, Araraquara, SP, Brazil.

3- DDS, MSc student, Department of Diagnosis and Surgery, Araraquara Dental School, UNESP - Univ. Estadual Paulista, Araraquara, SP, Brazil.

4- DDS, MSc, PhD, Adjunct Professor, Department of Morphology, Araraquara Dental School, UNESP - Univ. Estadual Paulista, Araraquara, SP, Brazil.

5- DDS, MSc, PhD, Associate Professor, Department of Diagnosis and Surgery, Araraquara Dental School, UNESP - Univ. Estadual Paulista, Araraquara, SP, Brazil.
\end{abstract}

Corresponding address: Prof. Joni Augusto Cirelli - Disciplina de Periodontia, Departamento de Diagnóstico e Cirurgia, Faculdade de Odontologia de Araraquara/Universidade Estadual Paulista - UNESP - Rua Humaitá, 1680 - $2^{\circ}$ andar - Araraquara - SP - 14801-903 - Brasil - Phone: +55-16-3301-6375 - Fax: +55-16-3301-6369 - e-mail: cirelli@foar.unesp.br

Received: November 19, 2009 - Modification: August 26, 2010 - Accepted: October 26, 2010

\section{ABSTRACT}

\begin{abstract}
Eurcation involvement in periodontal disease has been a challenge for the dentist. Objective: The aim of this study was to investigate root dimensions in the furcation area of 233 mandibular first molars. Material and Methods: Digital photomicrographs were used to obtain the following measurements on the buccal and lingual surfaces of each tooth: root trunk height (RT), horizontal interadicular distance obtained $1 \mathrm{~mm}$ (D1) and $2 \mathrm{~mm}$ (D2) below the fornix and interadicular angle (IA). Results: Mean \pm standard deviation of buccal and lingual furcation measurements were, respectively, $1.37 \pm 0.78 \mathrm{~mm}$ and $2.04 \pm 0.89 \mathrm{~mm}$ for RT; $0.86 \pm 0.39 \mathrm{~mm}$ and $0.71 \pm 0.42 \mathrm{~mm}$ for D $1 ; 1.50 \pm 0.48 \mathrm{~mm}$ and $1.38 \pm 0.48 \mathrm{~mm}$ for D2; $41.68 \pm 13.20^{\circ}$ and $37.78 \pm 13.18^{\circ}$ for IA. Statistically significant differences were found between all measured parameters for buccal and lingual sides $(p<0.05$, paired t test). Conclusions: In conclusion, the lingual furcation of mandibular first molars presented narrower entrance and longer root trunk than the buccal furcation, suggesting more limitation for instrumentation and worse prognosis to lingual furcation involvements in comparison to buccal lesions.
\end{abstract}

Key words: Furcation defects. Periodontics. Tooth root.

\section{INTRODUCTION}

Destructive periodontal disease is defined as an inflammatory condition of infectious primary cause, resulting in marginal alveolar bone resorption and attachment loss ${ }^{7}$. As the destruction of the periodontium progresses apically, the furcation of multirooted teeth is exposed, leading to irreversible bone loss in the interadicular area ${ }^{15}$.

The Glossary of Periodontal Terms defines furcation as "the anatomic area of a multirooted tooth where the roots diverge" and furcation invasion refers to the "pathologic resorption of bone within a furcation"2.

Effective instrumentation of furcation defects have always been a challenge for dentists ${ }^{15,29}$ due to the limited accessibility through the furcation entrances as well as the complex anatomy and morphology of molar teeth ${ }^{3,6,14}$. In addition, the morphology of the furcation region provides an environment favorable to bacterial plaque retention, which hampers professional and personal dental plaque control and affects positively the pathogenesis of periodontal destruction ${ }^{15,27}$. For those reasons, teeth with furcation involvement in periodontal disease have been shown to have a poorer prognosis than teeth without furcation involvement ${ }^{30}$. Therefore, the dentist must have a thorough understanding of furcation anatomy to accurately assess etiological factors, diagnose the furcation involvement and treat this condition appropriately ${ }^{13,14}$. Correct definition of the horizontal furcation involvement degree is important to choose the best treatment and determine the prognosis 
of furcated teeth. Several studies have focused on anatomical features of molar teeth $2,3,5,6,13,17,22,25,31$. The main anatomical considerations are: root trunk and furcation entrance dimensions, root surface area, and root separation distances.

According to previous studies, root trunk dimensions play an important role in the periodontal disease process due to its significant relation to both prognosis and treatment of the tooth ${ }^{13}$. Concerning the furcation entrance dimensions, a high percentage of mandibular first molars have width values equal to or less than $0.75 \mathrm{~mm}$. These values are smaller than the width of common curettes, which means that such instruments do not clean appropriately the dental surface in the furcation entrance area2,4,8,26. Thus, the effectiveness to instrument the furcation entrance area is compromised because such curettes do not fit in this area. Another feature of molar anatomy is root separation area in furcation region, which corresponds to the portion where the roots are separated by alveolar bone. The measurement of this area tends to increase apically demonstrating how divergent the roots can be ${ }^{31}$. Interadicular separation higher than or equal to $2 \mathrm{~mm}$ has been associated with the improvement of the furcation healing after regenerative therapies ${ }^{18}$.

The aim of the present study was to investigate the morphology of the furcation area of mandibular first molars comparing buccal and lingual sides, based on the limited information regarding this comparison.

\section{MATERIAL AND METHODS}

The experimental sample consisted of 233 mandibular first molars from the Human Tooth Bank of the Laboratory of Anatomy, Department of Morphology, Araraquara Dental School, UNESP, Brazil. For sample selection, teeth should present good conditions, in other words, teeth with caries, fused roots, calculus or restorative treatment that could interfere in the area of interest were excluded. The reasons for tooth extraction and any information about possible periodontal treatment before extraction could not be identified. The present study was approved by the Research Ethics Committee of UNESP (protocol number 13/05).

After selection of teeth, reference points were marked on the buccal and lingual surfaces of each tooth with a $0.3 \mathrm{~mm}$ graphite pencil, under a stereomicroscope Leica MZ6 (Leica Microsystems, Heerbrugg, Switzerland). Initially, a line was drawn on the cementoenamel junction (CEJ), and a point mark indicated the fornix of the furcation entrance. In each root, two other dots were performed, at $1 \mathrm{~mm}$ and $2 \mathrm{~mm}$ apical to the fornix point. After, the teeth were fixed in a red wax plate, in order to standardize tooth position and facilitate points and lines visualization. A small piece of millimeter paper was fixed on the tooth crown to allow resolution adjustment and stereometric measurements conversion from pixels to millimeter after taking the photomicrographs (Figure 1).

Photomicrographs were taken at $15 x$ magnification using a digital camera DXC-107 A/107 AP (Sony Electronics Inc., Tokyo, Japan). The images were transferred to a microcomputer and image analysis software (Jandel Sigma Scan Pro, Jandel Corporation, San Rafael, CA, USA) was used for stereometric analysis.

In the digital images, the following lines were drawn: line 1) a horizontal line tangent to the highest points of the CEJ of each root; line 2) a line parallel to the previous one, passing through the point of the fornix; lines 3) and 4) horizontal lines binding the points of each root, corresponding to $1 \mathrm{~mm}$ and $2 \mathrm{~mm}$ apical to the fornix. Lines 1 and 2 were used to obtain the measurement of the root trunk (RT). Lines 3 and 4 determined the

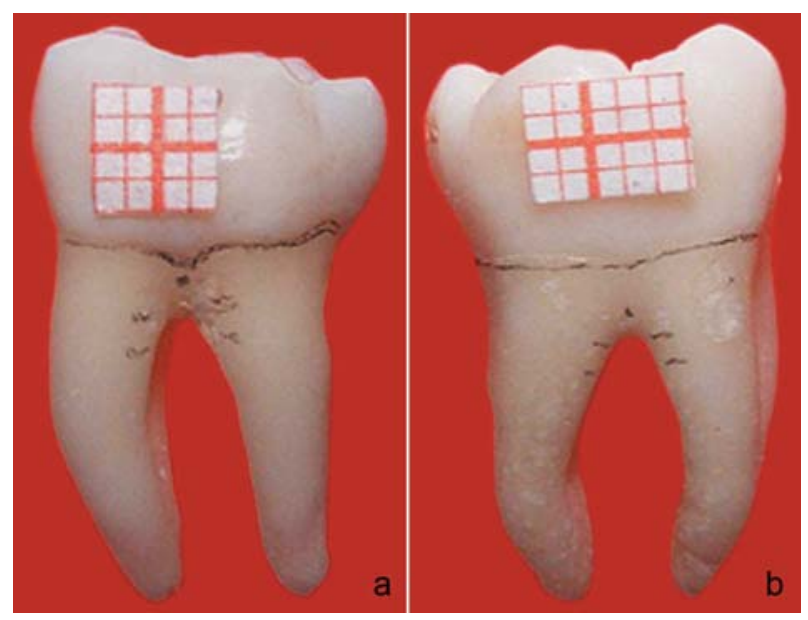

Figure 1- Buccal (a) and lingual (b) surfaces of a mandibular molar with line and reference points

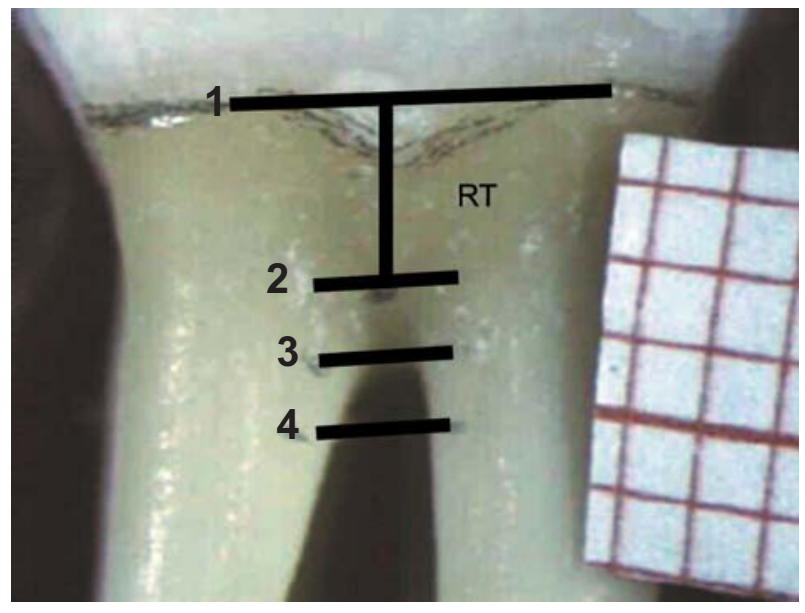

Figure 2- Reference lines 1, 2, 3 and 4 for Stereometric analysis 
interadicular distance.

After the lines were drawn, the following measurements were taken (Figure 2):

RT (root trunk) $=$ distance between the fornix and the highest point of the CEJ; D1 = distance between the mesial and distal roots $1 \mathrm{~mm}$ apical to the fornix; D2 = distance between the mesial and distal roots $2 \mathrm{~mm}$ apical to the fornix; IA (interadicular angle) $=$ angle of separation formed by the buccal and lingual roots of the furcation.

For the IA measurement, two lines were drawn along the inner wall of the mesial and distal root. The angle formed between the intersection of these two lines was recorded as the IA. Also, the average of three measurements corresponding to $1 \mathrm{~mm}$ in the grid paper on each digital image was obtained.
RT

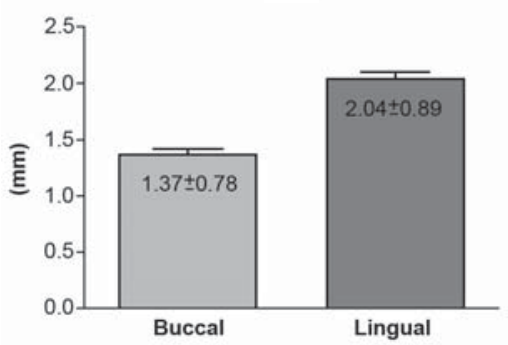

D1

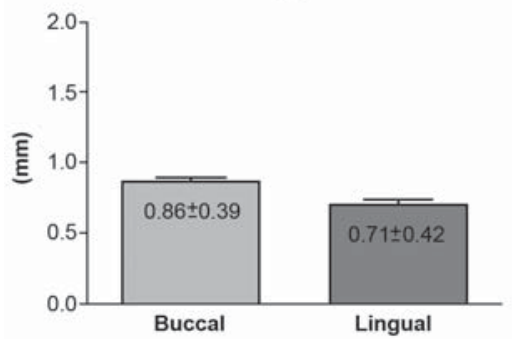

IA

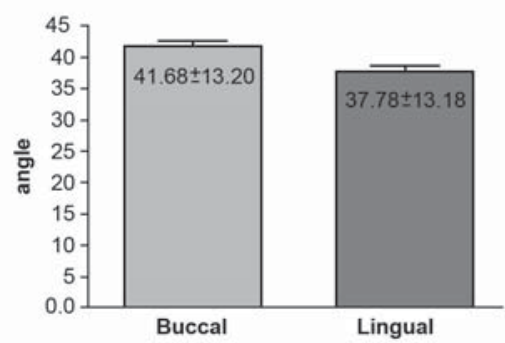

D2

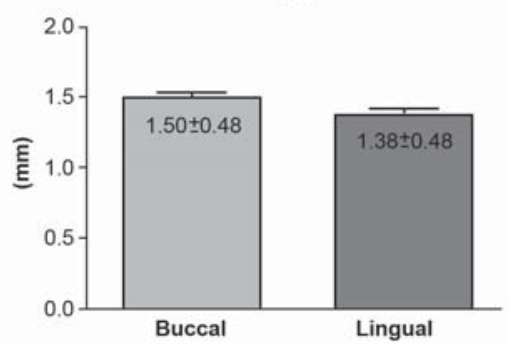

Figure 3- Mean and standard deviation (SD) values of root trunk height (RT), D1 and D2 linear measurements (mm) and interadicular angle $(I A)$ measured on the buccal and lingual surfaces of mandibular first molars $(n=233)$

RT

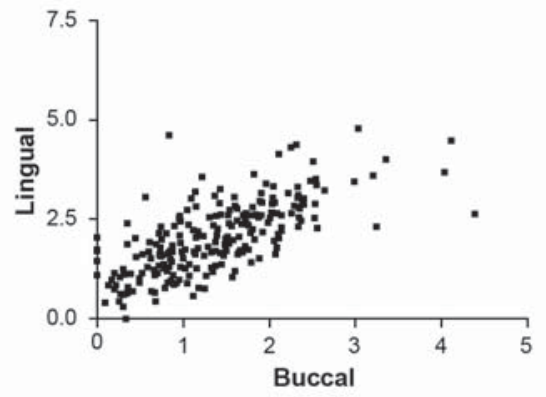

D1

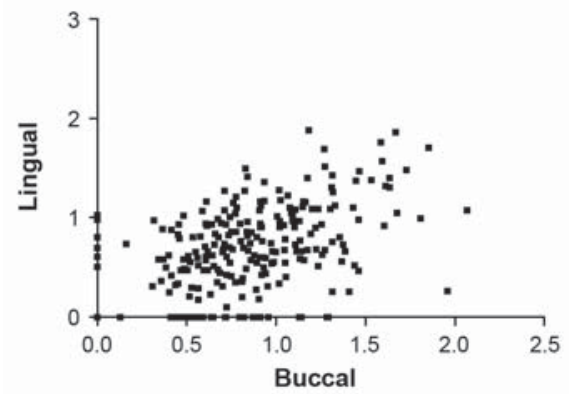

IA

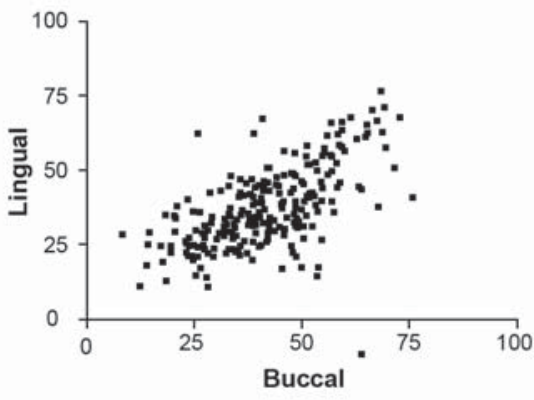

D2

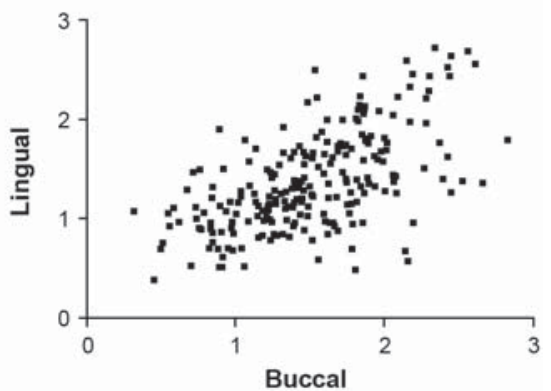

Figure 4- Pearson's correlation analysis between buccal and lingual surfaces for root trunk height (RT) (a), D1 (b), D2 (c) and interadicular angle (IA) (d) measurements $(n=233, p<0.001)$ 
This value allowed the conversion of all linear measurements from pixel to millimeters.

All measurements obtained in this study had normal distribution according to Gaussian curve, allowing parametric statistical analysis. Hence, all data were expressed as the mean \pm standard deviation of buccal and lingual furcations and comparative analysis between both sides was performed. For the evaluation of the variables RT, interadicular distance at $1 \mathrm{~mm}$ (D1) and $2 \mathrm{~mm}$ (D2) and IA statistical analysis was performed using a paired $t$ test, comparing buccal and lingual measures. Correlations between buccal and lingual measurements were calculated using the Pearson's correlation coefficient. The level of significance was set as $\mathrm{p} \leq 0.05$.

\section{RESULTS}

The results are presented by Figures 3 and 4. Statistically significant differences were found between all measured parameters for buccal and lingual sides $(p<0.05)$. The buccal RT was significantly shorter than the lingual RT $(p<0.001)$. The interadicular distance increased apically for both sides and the buccal side of the furcation presented greater D1 and D2 distances than the lingual side $(p<0.001)$. The IA of the lingual side was significantly smaller than that of the buccal side $(p<0.001)$.

\section{DISCUSSION}

Thorough knowledge of root anatomy is mandatory in periodontal therapies as it is intimately associated with the establishment of an accurate diagnosis and the correct choice of the treatment modality to provide optimal longterm prognosis of the teeth. The main finding of the present study was that the lingual furcation is anatomically different from the buccal furcation for all measurements evaluated, which probably affects disease establishment and prognosis.

The severity of furcation involvements is directly associated with the relationship between the amount of attachment loss and the RT length ${ }^{16}$. In the present study, morphometric analysis of mandibular first molar furcation area revealed longer lingual root trunk in comparison with buccal root trunk, as shown in Figure 3. This finding is in accordance with those of previous studies ${ }^{9,10,13,14}$. Short RT is more likely to develop early furcation involvement and attachment loss in the presence of periodontal disease because it has less surface area for periodontal attachment ${ }^{23}$. Even though, once the disease is installed, reduced RT lengths tend to lead to satisfactory periodontal treatment outcomes because of their easier access ${ }^{1,13-15,17,19,24,29}$. Also, short RT has been associated with longer individual roots and, consequently, greater potential for corrective therapy ${ }^{12,15}$. However, in the initial stages of the periodontal disease, long RT has a more favorable prognosis compared to the short one, because it protects the furcation from disease involvement. On the other hand, if the furcation is affected, the prognosis is poorer for longer RT, because the access for instrumentation is hampered ${ }^{15,24}$ and the roots are shorter indicating reduced chance of repair after periodontal therapy. In addition, it has been reported that there is no root trunk longer than $6 \mathrm{~mm}$, which implies that if you have $6 \mathrm{~mm}$ of attachment loss in a multirooted tooth, you are probably dealing with a tooth with furcation involvement ${ }^{5}$.

The furcation entrance measure is extremely important in anticipating the success of periodontal therapy. In this study, the lingual furcation was statistically narrower than the buccal furcation based on the interadicular distances (D1 and D2) and on the interadicular angle differences. This is the first study to find this particular feature of the first mandibular molar in respect to its interadicular width and relationship between the buccal and lingual surfaces. Narrow furcation implies an increased difficulty of access through furcation entrances for complete root debridement leading to a poor periodontal outcome $e^{2,4,8,24}$. On the other hand, longer root trunk ends up compensating for this characteristic of the lingual side because it makes the furcation access more difficult, preventing early periodontal involvement. This is a positive relationship between root trunk dimension and interadicular distance/angle found in this study, since these features reduce the chance of dental plaque accumulation in the furcation entrance.

Curettes are the manual instruments commonly used during periodontal therapy to produce a smooth and biologically acceptable surface and to permit satisfactory healing ${ }^{11,13}$. The blades of these instruments play an important role since they must present a width that allows correct and effective root debridement. However, narrow furcation entrance dimensions may complicate the periodontal treatment of furcation involvements ${ }^{4}$ as the active tip of most instruments (e.g.: Gracey curette) present width of 0.95-1.2 mm and do not fit in the furcation region ${ }^{2,26}$. Considering the furcation entrance as well as the blade width of periodontal instruments, various studies have found this type of difficulty in periodontal therapy in molar furcations ${ }^{2,26}$.

It is important to emphasize that the interadicular distance of $1 \mathrm{~mm}$ from the furcation fornix (D1) is the most critical measurement obtained because it is narrower and more coronal, corresponding almost to the furcation roof of the teeth. This is 
the first area to be infected when the furcation is involved, and the most difficult region for the dentist to access and perform a correctly instrumentation during the periodontal treatment. A recent study evaluating the radiographic characteristics of furcation involvements showed that narrower root furcations may have better outcomes after nonsurgical periodontal therapy because they are less exposed to contaminants and have less root irregularities ${ }^{28}$.

Regarding regenerative therapy, Pepelassi, et al. ${ }^{18}$ (1991) have stated that interadicular separation of $2 \mathrm{~mm}$ or greater provides more favorable regenerative healing. On the other hand, Pontoriero, et al. ${ }^{20,21}(1988,1989)$ have found that furcation width - interadicular separation area - greater than $4 \mathrm{~mm}^{2}$ and entrance height of $3 \mathrm{~mm}$ or greater failed to heal with complete defect closure. This means that there may be limitation values for interadicular separation - size and height of the furcation defect - that promotes a favorable healing on regenerative therapies.

The positive correlation obtained in this study between buccal and lingual sides suggests that teeth with difficult access to one surface will probably have the same difficulty on the opposite side. This finding has implications for clinical therapeutic practice.

Reports by other studies confirm that the morphology/anatomy of mandibular first molars is extremely complex and must be thoroughly understood to improve success rate of periodontal therapy $15,22,26$ The results of this study call attention to the importance of the furcation dimensions in these teeth to a better clinical practice, involving diagnosis, prevention and treatment of periodontal disease.

\section{CONCLUSIONS}

This is the first study that compared buccal and lingual surfaces of first mandibular molar demonstrating significant differences based on the interadicular width. According to the present findings, mandibular first molars have anatomically narrower interadicular distance and greater root trunk height in the lingual surface than in the buccal surface. These observations have implications for clinical practice in the treatment planning and prognosis determination of furcation involvements in patients with periodontal disease.

\section{ACKNOWLEDGEMENTS}

The authors wish to thank Mr. Marcelo Brito Conti, laboratory technician from the Department of Morphology, for technical support.

\section{REFERENCES}

1- Al-Shammari KF, Kazor CE, Wang HL. Molar root anatomy and management of furcation defects. J Clin Periodontol. $2001 ; 28(8): 730-40$.

2- Bower RC. Furcation morphology relative to periodontal treatment. Furcation entrance architecture. J Periodontol. $1979 ; 50(1): 23-7$.

3- Bower RC. Furcation morphology relative to periodontal treatment. Furcation root surface anatomy. J Periodontol. $1979 ; 50(7): 366-74$.

4- Chiu BM, Zee KY, Corbet EF, Holmgren CJ. Periodontal implications of furcation entrance dimensions in Chinese first permanent molars. J Periodontol. 1991;62(5):308-11.

5- Dunlap RM, Gher ME. Root surface measurements of the mandibular first molar. J Periodontol. 1985;56(4):234-8.

6- Gher ME, Vernino AR. Root morphology - clinical significance in pathogenesis and treatment of periodontal disease. J Am Dent Assoc. $1980 ; 101(4): 627-33$.

7- Heitz-Mayfield LJ. How effective is surgical therapy compared with nonsurgical debridement? Periodontol 2000. 2005;37:72-87. 8- Hou GL, Chen SF, Wu YM, Tsai CC. The topography of the furcation entrance in Chinese molars. Furcation entrance dimensions. J Clin Periodontol. 1994;21(7):451-6.

9- Hou GL, Chen YM, Tsai CC, Weisgold AS. A new classification of molar furcation involvement based on the root trunk and horizontal and vertical bone loss. Int J Periodontics Restorative Dent. 1998;18(3):257-65.

10- Hou GL, Tsai CC. Cervical enamel projection and intermediate bifurcational ridge correlated with molar furcation involvements. J Periodontol. 1997;68(7):687-93.

11- Jones SJ, Lozdan J, Boyde A. Tooth surfaces treated in situ with periodontal instruments. Scanning electron microscopic studies. Br Dent J. 1972;132(2):57-64.

12- Kapin SH, Eskow RN. Furcation invasions: correlating a classification system with therapeutic considerations. Part III. Sectioning teeth in the treatment of furcation invasions. Compend Contin Educ Dent. 1984;5(8):612-4, 617, 619.

13- Kerns DG, Greenwell H, Wittwer JW, Drisko C, Williams JN, Kerns LL. Root trunk dimensions of 5 different tooth types. Int J Periodontics Restorative Dent. 1999;19(1):82-91.

14- Mandelaris GA, Wang HL, MacNeil RL. A morphometric analysis of the furcation region of mandibular molars. Compend Contin Educ Dent. 1998;19(2):113-6,118-20.

15- Mardam-Bey W, Majzoub Z, Kon S. Anatomic considerations in the etiology and management of maxillary and mandibular molars with furcation involvement. Int J Periodontics Restorative Dent. 1991;11(5):398-409.

16- Matthews DC, Tabesh M. Detection of localized tooth-related factors that predispose to periodontal infections. Periodontol 2000. 2004;34:136-50.

17- Paolantonio M, Di Placido G, Scarano A, Piattelli A. Molar root furcation: morphometric and morphologic analysis. Int J Periodontics Restorative Dent. 1998;18(5):488-501.

18- Pepelassi EM, Bissada NF, Greenwell H, Farah CF. Doxycyclinetricalcium phosphate composite graft facilitates osseous healing in advanced periodontal furcation defects. J Periodontol. 1991;62(2):106-15.

19- Plagmann HC, Holtorf S, Kocher T. A study on the imaging of complex furcation forms in upper and lower molars. J Clin Periodontol. 2000;27(12):926-31.

20- Pontoriero R, Lindhe J, Nyman S, Karring T, Rosenberg E, Sanavi $F$. Guided tissue regeneration in degree II furcationinvolved mandibular molars. A clinical study. J Clin Periodontol. 1988;15(4):247-54.

21- Pontoriero R, Lindhe J, Nyman S, Karring T, Rosenberg E, Sanavi F. Guided tissue regeneration in the treatment of furcation defects in mandibular molars. A clinical study of degree III involvements. J Clin Periodontol. 1989;16(3):170-4. 
22- Porciuncula HF, Porciuncula MM, Zuza EP, Toledo BE. Biometric analysis of the maxillary permanent molar teeth and its relation to furcation involvement. Braz Oral Res. 2004;18(3):187-91.

23- Porciuncula HF, Zuza EP, Porciuncula MM, Toledo BE, Mendes AJ. Root trunk height as a risk factor for periodontal furcation involvement in maxillary first molars: an in vitro study. J Int Acad Periodontol. 2007;9(3):89-95.

24- Roussa E. Anatomic characteristics of the furcation and root surfaces of molar teeth and their significance in the clinical management of marginal periodontitis. Clin Anat. 1998;11(3):17786.

25- Santana RB, Uzel MI, Gusman H, Gunaydin Y, Jones JA, Leone $\mathrm{CW}$. Morphometric analysis of the furcation anatomy of mandibular molars. J Periodontol. 2004;75(6):824-9.

26- Santos KM, Pinto SC, Pochapski MT, Wambier DS, Pilatti GL, Santos FA. Molar furcation entrance and its relation to the width of curette blades used in periodontal mechanical therapy. Int J Dent Hyg. 2009;7(4):263-9.
27- Svärdström G, Wennström JL. Prevalence of furcation involvements in patients referred for periodontal treatment. J Clin Periodontol. 1996;23(12):1093-9.

28- Vale HF, Del Peloso Ribeiro E, Bittencourt S, Nociti FH, Jr, Sallum EA, Casati MZ. Radiographic characteristics of furcation involvements in mandibular molars as prognostic indicators of healing after nonsurgical periodontal therapy. J Am Dent Assoc. $2009 ; 140(4): 434-40$.

29- Waerhaug J. The furcation problem. Etiology, pathogenesis, diagnosis, therapy and prognosis. J Clin Periodontol. 1980;7(2):7395.

30- Wang HL, Burgett FG, Shyr Y, Ramfjord S. The influence of molar furcation involvement and mobility on future clinical periodontal attachment loss. J Periodontol. 1994;65(1):25-9.

31- Ward C, Greenwell H, Wittwer JW, Drisko C. Furcation depth and interroot separation dimensions for 5 different tooth types. Int J Periodontics Restorative Dent. 1999;19(3):251-7. 